\title{
Investigation On Working Postures And Musculoskeletal Disorders Among Office Workers In Putrajaya
}

\author{
Che Hazwani Che Mansor ${ }^{1, a}$, Safial Eqbal Zakaria ${ }^{2, b}$, Siti Zawiah Md Dawal ${ }^{3, c}$ \\ ${ }^{1}$ Faculty of Engineering, University of Malaya, 50603 Kuala Lumpur, Malaysia \\ ${ }^{2}$ Faculty of Medicine and Health Sciences, Universiti Putra Malaysia, 43400 UPM Serdang, \\ Selangor Malaysia \\ ${ }^{3}$ Faculty of Engineering, University of Malaya, 50603 Kuala Lumpur, Malaysia \\ achehazwani@mmea.gov.my, beqbal_upm@yahoo.com, 'csitizawiahmd@um.edu.my
}

Keywords: Working postures, musculoskeletal disorders, office ergonomics

\begin{abstract}
The cross-sectional study was conducted amongst thirty eight government supporting staff who mainly doing sedentary task in Malaysia Maritime Enforcement Affair Division (MMEAD) (49\%) and Ministry of Health (MOH) (51\%) in Putrajaya. The investigation aims to determine the association between working postures and musculoskeletal disorders (MSD) among office workers where all respondents were selected in 5 sections; administrative (64\%), financial $(12 \%)$, counter/assistant (12\%), human resources management (6\%) and procurement section (6\%). Self-reported questionnaires using Nordic questionnaire were used in this investigation. Besides, posture analysis was done based on Rapid Upper Limb Assessment (RULA) and office ergonomics checklist adapted from Texas Department of Insurance, Division of Workers Compensation (2008) were used as the instrumentations of this investigation. Face validity and reliability testing for the questionnaire and intra tester reliability for the posture assessment was done to ensure true quality of the results and analysis. From the analysis, the highest prevalence of MSD complained is lower back pain (LBP) $57.9 \%$ while the lowest prevalence is elbow pain (EP) $2.6 \%$. Result shows $31.6 \%$ of the respondents believe the pain is caused by working activities. Based on the ergonomics checklist, MMEAD shows the highest mean (64.84\%) of non compliance, where all the workstations scored more than 50\% compared with $\mathrm{MOH}$. Based on RULA observation, most of the workstation scores in action level 3 (grand score 5-6). In conclusion, the high complained of MSD is due to awkward postures, unsuitable workstation and lack of knowledge related to the areas to apply in everyday routine and it shows that working postures have a direct contribution on MSD complained by the office workers in Putrajaya.
\end{abstract}

\section{Introduction}

Ergonomics is the science of improving employee performance and well being in relation to job task, equipment and environment. Ergonomic application in working environment will give influence to the productivity of work. The effectiveness and achievement of this issue can reduce health-related problems, risk of injuries and also increase workers' satisfaction and comfort while working.

A study conducted by National Institute of Safety and Health Malaysia (NIOSH, Malaysia) and Japanese International Cooperation Agency (JICA) found out that using computers and equipment long hours will cause health problems especially Low Back Pain (LBP) among the workers. Working with computer workstations usually expose the workers to sustain in static and awkward body posture, reaching, prolong sitting and repetitive hand or finger movement especially while operating keyboard and mouse. This factor may cause extreme physiological strain on the muscles, ligaments and spinal disc which can contribute to musculoskeletal complained (MSD) [1].

Presently, Malaysian government had implemented the use of computer workstation in most of daily tasks. Therefore, it is undeniable that the rise of adverse health effect associated with the implementation of computer workstation such as musculoskeletal disorders (MSD), cumulative 
trauma disorders (CTD and CTS) and computer visual syndrome (CVS) do occur to the workers. Having said that, posture shows the most influenced factor contributed to the complaint of MSD among office workers. Therefore, this study is important to further investigate the effects of working postures at computer workstation as there are approximately two million workers employed by the Malaysian government including permanent and temporary or associate contract workers [2][3].

This study also make used of RULA assessment. RULA was developed by Atamney and Corlett in 1993 as an assessment tool to evaluate posture, force and muscle used [4][5]. The aim of RULA is to evaluate musculoskeletal risks caused mainly by sedentary tasks where upper body demands were high [6]. In RULA observation, three main steps were involved, which is 1) selecting of posture, 2) scoring the posture by using a scoring sheet, and 3) converting the score into action level. Body segment was divided into Group A and B. Group A includes the upper and lower arms and wrist, while group B includes the neck, trunk and legs [6].

The main focus of this research is to investigate the effects of working postures on sedentary computer workstations where it focus on government supporting staff who mainly doing sedentary work as their major tasks. This study will show whether there is a significant relationship between working postures and MSD complained by the office workers in Putrajaya or not.

\section{Methodology}

\subsection{Study design}

The cross-sectional study was conducted amongst government supporting staff in Putrajaya. Thirty eight workers who are mainly doing sedentary task were chosen to be the case study. This study was done in Malaysia Maritime Enforcement Affair Division (MMEAD) and Ministry of Health (MOH) in Putrajaya. The respondent was selected based on inclusive criteria, whereby; workers who did not comply the criteria were excluded from the study. The criteria are:

$\begin{array}{ll}\text { i. } & \text { Malaysia citizen } \\ \text { ii. } & \text { Supporting staff } \\ \text { iii. } & \text { Mainly task is sedentary work or computer workstation } \\ \text { iv. } & \text { Do not have permanent physical disabilities }\end{array}$

The respondent was selected in 5 sections which are administrative, financial, counter/assistant, human resources management and procurement section.

\subsection{The questionnaires}

Questionnaire, RULA worksheet and office ergonomics checklist are the instrumentations used throughout this study. In order to ensure the true quality of the techniques and findings of this study, there are some quality assurances taken into considerations. Face validity and reliability testing were done for the questionnaire and intra tester reliability was done for the posture assessment. For posture assessment, only one observer required to analyze the result so that biasness of the study can be reduced.

\subsection{Data analysis}

The data was analyzed by using Statistical Package for Social Sciences (SPSS) version 18 for statistical analysis. Univariate analysis of descriptive distribution was used to determine the mean, standard deviation, frequency and percentage for socio-demography data and ergonomics checklist. RULA analysis was analyzed based on grand score and action level as described by McAtamney \& Corlett (1992). 


\section{Results}

The data was collected among supporting staff of two government agencies in Putrajaya, which are Malaysian Maritime Enforcement Affair Division (MMEAD) (49\%) and Ministry of Health $(\mathrm{MOH})(51 \%)$. Table 1 below show the background information of the respondents for this study. The summary of respondent's occupational information shown in Table 2.

Table 1 Background information

\begin{tabular}{|l|c|c|}
\hline \multicolumn{1}{|c|}{ Variable } & $\mathrm{n}$ & $\%$ \\
\hline Gender: & 14 & 42.4 \\
Male & 19 & 57.6 \\
Female & & \\
\hline Marital Status: & 13 & 39.4 \\
Single & 20 & 60.6 \\
Married & & \\
\hline Transport: & 25 & 75.8 \\
Car & 5 & 15.2 \\
Motorcycle & 2 & 6.1 \\
Bus/public transport & 1 & 3 \\
Walking & & \\
\hline Education: & 1 & 3 \\
PMR/SRP & 17 & 51.5 \\
SPM & 13 & 39.4 \\
STPM/Diploma & 2 & 6.1 \\
Degree & & \\
\hline Age: & 17 & 53.1 \\
20-30 & 9 & 28.1 \\
31-40 & 2 & 6.3 \\
41-50 & 4 & 12.5 \\
Above 50 & & \\
\hline
\end{tabular}

Table 2 Occupational background

\begin{tabular}{|l|c|c|}
\hline \multicolumn{1}{|c|}{ Variable } & $\mathrm{n}$ & $\%$ \\
\hline Extra work: & 3 & 7.9 \\
Yes & 35 & 92.1 \\
No & 18 & 47.4 \\
\hline Home/physical activity: & 19 & 50 \\
Yes & 1 & 2.6 \\
No & 36 & 94.7 \\
\hline Gardening: & 13 & 34.2 \\
Yes & 25 & 65.8 \\
No & \multicolumn{2}{|c|}{ mean \pm SD } \\
\hline Sport: & \multicolumn{2}{|c|}{$75.48 \pm 96.535$} \\
Yes & \\
No & \multicolumn{2}{|c|}{} \\
\hline
\end{tabular}


The first objective of the study is to determine the prevalence of MSD among supporting staff in two government agencies in Putrajaya. The study identified that for life time prevalence of MSD, the highest complain is showed by lower back pain (LBP) $57.9 \%$, followed by neck pain (NP) $55.3 \%$, shoulder pain (SP) $44.7 \%$, upper back pain (UBP) $42.1 \%$, knee \& leg pain (KLP) $18.4 \%$, arm pain (AP) $7.9 \%$, hip \& thigh pain (HTP) $5.3 \%$ and elbow pain (EP) $2.6 \%$. The same trend was shown in 7 days prevalence, but the highest complained was NP with $31.6 \%$ of the respondent having pain at least once during 7 days of data collection. Among the respondents who experience the pain, $31.6 \%$ of them believe the pain is caused by working activities. Table 3 below describe the prevalence of MSD among respondents.

Table 3 Prevalence of MSD

\begin{tabular}{|l|c|c|c|c|}
\hline Body Parts & $\begin{array}{c}\text { Lifetime } \\
\mathrm{n}(\%)\end{array}$ & $\begin{array}{c}\text { Seven days } \\
\mathrm{n}(\%)\end{array}$ & $\begin{array}{c}\text { Pain preventing from doing } \\
\text { normal activities n (\%) }\end{array}$ & $\begin{array}{c}\text { Pain because of } \\
\text { working factors n (\%) }\end{array}$ \\
\hline Neck & $21(55.3)$ & $12(31.6)$ & $3(7.9)$ & $13(34.2)$ \\
\hline Shoulder & $17(44.7)$ & $9(23.7)$ & $3(7.9)$ & $11(28.9)$ \\
\hline Elbow & $1(2.6)$ & $1(2.6)$ & 0 & 0 \\
\hline Arm & $3(7.9)$ & $3(7.9)$ & $1(2.6)$ & $1(2.6)$ \\
\hline Upper back & $16(42.1)$ & $10(26.3)$ & $3(7.9)$ & $11(28.9)$ \\
\hline Lower back & $22(57.9)$ & $10(26.3)$ & $4(10.5)$ & $12(31.6)$ \\
\hline Hip \& thigh & $2(5.3)$ & $2(5.3)$ & $1(2.6)$ & 0 \\
\hline Knee \& leg & $7(18.4)$ & $6(15.8)$ & $2(5.3)$ & $1(2.6)$ \\
\hline
\end{tabular}

Based on the ergonomics checklist, the mean score of the overall respondents is $61 \%$. Majority (97\%) of the workstation score more than $50 \%$ of non compliance based on ergonomics criteria that have been investigated. Based on the result, MMEAD shows the highest mean $(64.84 \%)$ of non compliance, where all the workstations scored more than 50\% compared with $\mathrm{MOH}$. Table 4 shows the summary score of ergonomics checklist.

Table 4 Ergonomics Checklist

\begin{tabular}{|l|c|c|c|}
\hline Agency & All & MMEAD $(\mathrm{n}=17)$ & MOH $(\mathrm{n}=16)$ \\
\hline Mean \pm SD & $61.03 \pm 8.14$ & $64.84 \pm 6.35$ & $57.44 \pm 8.15$ \\
\hline Median & 62.5 & 63.5 & 8.15 \\
\hline
\end{tabular}

In general, the result of non compliance ergonomics checklist found in this study is similar to a study done by Shamsul Bahri (2008) in government office in Malaysia, where from all the 7 government agencies participated in the study, approximately $43 \%$ of the total respondents did not comply with ergonomics checklist. The major issues found were unsuitable chair and workstation arrangement which exposed them to high risk of developing MSD [7].

Table 5 RULA score

\begin{tabular}{|l|c|l|c|}
\hline Department & Grand Score & \multicolumn{1}{|c|}{ Action Level } & $\mathrm{n}(\%)$ \\
\hline \multirow{2}{*}{ MMEAD } & $5-6$ & 3 (Investigation and changes are required soon) & $2(66.7)$ \\
\cline { 2 - 4 } & $7-8$ & 4 (Investigation and changes are required immediately & $1(33.3)$ \\
\hline MOH & $5-6$ & 3 (Investigation and changes are required soon) & $3(100)$ \\
\hline
\end{tabular}

For RULA analysis, it was done among six respondents; where three respondents were randomly selected from each department. The purpose of this assessment is to observe the workers' body posture during working hour in front of computer or in their workstations. Based on the result, $66.7 \%$ of the workers in MOH score 5 in RULA analysis and $66.7 \%$ of the workers in MMEAD score 6 . 
There are similarities between finding in this study and study done by Shamsul (2008) among government workers in Malaysia. Shamsul (2008) also found that none of the workstation in 7 government departments was categorized in action level 1 and most of the workstation score action level 3 in RULA analysis. Table 5 show the RULA Score in two government agencies taking part in this study.

\section{Conclusions}

In conclusion, all the objectives of this study had been accomplished. Therefore, the final conclusions of this study are the highest prevalence of MSD complained is lower back pain (LBP) $57.9 \%$, followed by neck pain (NP) 55.3\%, shoulder pain (SP) 44.7\%, upper back pain (UBP) 42.1, knee \& leg pain (KLP) $18.4 \%$, arm pain (AP) $7.9 \%$, hip \& thigh pain (HTP) $5.3 \%$ and elbow pain (EP) $2.6 \%$. Based on ergonomics checklist, the major problems that have been identified are awkward postures, unsuitable workstation arrangement, unsuitable chair and inadequate training in the related area. Furthermore, based on RULA observation, none of the workstation scores action level 1 and 2. With most of the workstation scores in action level 3 (grand score 5-6). In conclusion, based on ergonomics checklist and RULA observation, the high complained of LBP and NP (above $50 \%)$ is due to awkward postures of back and neck areas especially during reaching the object and referred to the document, unsuitable workstation arrangement that promote awkward postures, unsuitable chair which can cause faster fatigue of the muscle and lack of knowledge in the related areas to apply in everyday routine.

\section{References}

[1] Morse, T. F., Waren, N., Dillon, C. and Diva, U. A population based survey of ergonomics risk factors in Connecticut: distribution by industry, occupation and demography. Conn. Med. 71(5) (2007) 261-8.

[2] Department of Occupational Safety and Health, Malaysia. Guideline on occupational safety and health for working with video display units (VDU'S) (2003).

[3] Department of Safety and Health, DOSH. Malaysia Occupational Safety and Health Profile (2010).

[4] Diniz, F., Fernanda, D. d., Maria, A. A., Ana, C. C., Juliana, C. S., \& Paulo, J. A. Comparison of methods RULA and REBA for evaluation of postural stress in odontological services. $3 r d$ International Conference on Production Research - Americas' Region (ICPR-AM06) (2006).

[5] Hignett, S., \& Atamney, L. M. REBA and RULA: Whole body and upper limb rapid tools. In W. S. Marras, \& W. Karwowski (Eds.), Fundamentals and Assessmnet Tools for Occupational Ergonomics (2nd ed., pp. 1-12). Boca Raton: Taylor \& Francis Group (2006).

[6] Atamney, L. M., \& Corlett, E. N. RULA: A Survey Method for the Investigation of WorkRelated Upper Limb Disorders. Applied Ergonomics , 24, (1993) 91-99.

[7] Shamsul Bahri, M. T., Muhammad Aahar, M. N., Mohd Rafee, B. B., Nurul Asyiqin, M. A. And Ng, Y. G. Ergonomics risk factors and health effects among visual display unit (VDU) users among Malaysian Government servants. Journal of Medical Safety, (2009) 2, 23-36. 